\title{
An Analysis of the Interaction Effect of Benefit and Cost on Cloud Computing Service
}

\author{
Park So Yeon ${ }^{+} \cdot$ Kim Yongwon ${ }^{++}$
}

\begin{abstract}
IT has been receiving increasing attention for cloud computing services. However, despite a lot of attention, there are limitations of existing research on cloud computing services. There are researches respectively about the benefits and costs that would occur if you choose a cloud computing services. However, in real life, consumers should be considered about the benefits and costs at the same time if they choose and use a cloud computing service. Therefore, this study examines the interaction effect of benefits and costs on cloud computing service. The findings demonstrate that three independent variables(usefulness, social influence, and innovativeness) positively $(+)$ affect the perceived value. However, showed the benefits and costs of interaction effects analysis, usefulness and innovation on the cost influence the perceived value in statistics. The interaction of the usefulness \& cost shows negative(-) effect and the interaction of the innovativeness \& cost has positve(+) effect on the perceived value. In conclusion, this study provide that consumers need to consider costs with benefits when they use a cloud computing service.
\end{abstract}

Keywords : Cloud Computing Service, Benefit, Cost, Interaction Effect

\section{클라우드 컴퓨팅 서비스 혜택과 비용의 상호작용 효과에 관한 연구}

\author{
박 소 연 ${ }^{+}$김 용 원 ${ }^{\dagger+}$
}

\begin{abstract}
요 약
클라우드 컴퓨팅 서비스에 대한 관심이 높아지고 있다. 하지만 많은 관심에도 불구하고 클라우드 컴퓨팅 서비스에 대한 기존 연구는 한계점 이 있다. 선행연구들은 이 서비스가 제공하는 많은 혜택에 대한 연구와 이 서비스를 선택할 경우 발생할 수 있는 문제점에 대해 독립적으로 연 구하고 있다. 하지만 실제 생활에서 소비자는 클라우드 컴퓨팅 서비스를 선택할 경우 혜택과 비용에 대해 동시에 고려한다. 따라서 본 연구에 서는 클라우드 컴퓨팅 서비스 선택 시 혜택과 비용에 대한 상호작용 효과를 탐색적으로 분석하였다. 분석 결과 독립변수로써 유용성, 사회적영 향, 그리고 혁신성은 인지된 가치에 모두 정(+)의 유의한 영향을 주었다. 하지만 혜택과 비용과의 상호작용 효과 분석 결과 유용성과 혁신성만 이 비용과의 인지된 가치에 대해 통계학적으로 유의한 것으로 나타났다. 유용성은 비용과의 인지된 가치에 대해 상호작용 효과에 대해 음(-)의 결과가 나타났으며, 혁신성은 비용과의 인지된 가치에 대해 상호작용 효과 검정 결과 정(+)의 상호작용 효과가 있는 것으로 나타났다. 결국 본 연구는 클라우드 컴퓨팅 서비스를 선택할 경우 소비자가 느끼는 혜택의 경우 비용을 고려할 때 인지된 가치에 서로 다른 영향을 줄 수 있음을 실증했다는 점에서 의의가 있다고 하겠다.
\end{abstract}

키워드 : 클라우드 컴퓨팅 서비스, 혜택, 비용, 상호작용효과

\section{1. 서 론}

1990년대 인터넷 혁명에 이어 2000년대 후반부터는 클라우 드 컴퓨팅 (Cloud computing) 시대가 도래하였다[1]. 클라우

\footnotetext{
† 정 회 원 : 연세대학교 정보대학원 석사과정

†† 정 회 원 : 연세대학교 방송통신정책연구소 선임연구원 논문접수: 2012 년 10월 25일 수 정 일 : 1 차 2012 년 11 월 26 일 심사완료 : 2012년 11월 30일

* Corresponding Author: Kim Yongwon(kkjerry@yonsei.ac.kr)
}

드 컴퓨팅은 사용자들이 $\mathrm{PC}$ 와 모바일 기기 등 다양한 단말기 $\mathrm{S}$ 를 통하여 사용료를 지불하고 Information and Communication Technology (ICT) 자원을 빌려 쓰는 새로운 패러다임 이다[2]. 이는 자원 절감 및 효율성 제고, 그린 ICT에 대한 지속적인 사회적 요구로 인해 각광받고 있다. 국내에서는 2009년 12월 30일 지식경제부와 방송통신위원회, 행정안전부 가 공동으로 ‘클라우드 컴퓨팅 활성화 종합계획’을 발표하였 다. 그리고 최근에는 클라우드 컴퓨팅 발전 및 이용자 보호에 관한 법률, 일명 ‘클라우드 법’ 제정이 본격화되고 있다. 
향후 클라우드 컴퓨팅 서비스와 관련한 매출 및 시장은 확장될 것이라고 예측한다[2]. 2009년부터 2014년까지 세계 클라우드 컴퓨팅 시장이 연평균 $34 \%$ 성장하고, 세계시장 규 모는 2009년 796억 달러에서 2014년에는 3,434억 달러가 될 것으로 전망한다[3]. 그러나 이러한 성장에는 정보 보안 문 제와 시간적, 경제적 비용 문제 등의 위험도 따른다. G메일 은 구글에서 제공하는 SaaS (Software as a Service) 방식 의 대표적인 클라우드 컴퓨팅 서비스이다[4]. 그러나 2009년 9월 24일부터 26일까지 G메일에 부분적인 장애가 발생하였 다. 2007년 이후 전세계 주요 13개 클라우드 서비스 제공업 체에 발생한 다운타임은 총 568시간에 이른다.

기존 연구들에서는 보안 이슈를 제외하고는 클라우드 컴 퓨팅 서비스의 위험 또는 비용의 특성에 관련된 연구가 부 족하다. 또한 클라우드 컴퓨팅 서비스를 이용하고자 할 때, 얻을 수 있는 혜택과 지불해야 할 비용 사이의 상호작용 관 계에 대한 연구는 거의 이루어지지 않은 실정이다. 따라서 본 연구에서는 클라우드 컴퓨팅 서비스의 특성 가운데 혜택 과 비용의 특성을 구분하고, 혜택과 비용의 인지된 가치에 대한 상호작용 효과에 관해 밝히고자 한다.

\section{2. 이론적 고찰}

\section{1 클라우드 컴퓨팅 서비스 (Cloud computing service)의 정의 및 특성}

클라우드 컴퓨팅이란 용어는 2006년 9월에 구글사 직원인 '크리스토프 비시글리아 (Christophe Bisciglia)'가 유휴 컴퓨 팅 자원에 대한 활용을 제안하면서 처음 사용되었다. 클라 우드 컴퓨팅 서비스 정의는 연구 기관이나 학자마다 약간씩 차이를 보이고 있다. Gartner는 클라우드 컴퓨팅 서비스를 인터넷 기술을 활용해서 고객들에게 높은 수준의 확장성을 지닌 IT 자원들을 서비스로 제공하는 컴퓨팅이라고 정의하 였다[5]. CPNI는 클라우드 컴퓨팅 서비스를 임대에 기반을 두고 네트워크상에서 고객의 서비스 요구사항을 확대하거나 축소하는 능력으로 고객에게 제공된 IT 서비스의 집합이라 하였다[6]. 또한 NIST (National Institute of Standards and Technology)에서는 클라우드 컴퓨팅 서비스를 통해 최소의 관리 노력이 요구되고 서비스 사업자와의 상호 작용으로 신 속한 서비스 제공이 가능하다고 분석했다[7].

공통적으로 살펴보면 클라우드 컴퓨팅이란 가상 공간에서 정보들이 공유 및 통합되어 사용자의 기호에 따라 소프트웨 어, 플랫폼, 인프라 등을 실시간으로 활용할 수 있게 함으로 써 정보의 통제와 관리, 검색 및 조정 과정이 혁신적인 수 준으로 효율화되는 미래형 컴퓨팅 체제라고 할 수 있다.

\section{2 클라우드 컴퓨팅 서비스의 장점}

클라우드 컴퓨팅 서비스를 도입할 경우 사용자가 얻을 수 있는 장점 및 혜택은 크게 다음과 같다. 첫째, 클라우드 컴 퓨팅 서비스는 사용자가 특정한 장치나 위치에 상관없이 시 스템에 접근이 가능하므로 업무 성과와 생산성을 향상시켜
유용성을 증대시킨다 $[2,8]$. 상시적인 협업 체계를 구축할 수 있어 업무 효율성이 높아진다[9]. 둘째, 클라우드 컴퓨팅 서 비스 사용자는 자신의 컴퓨터에 별도의 ICT 자원을 구입 및 설치하지 않고도 인터넷을 기반으로 컴퓨팅 자원을 이용 하기 때문에 장기적으로는 비용 절감 효과가 있다[1]. 셋째, ICT 자원을 서로 공유할 수 있어 탄소 배출량 감소를 통한 그린 ICT 실현을 기대할 수 있다[2]. 넷째, 최근 사회적으로 긍정적인 평가를 받고 있는 클라우드 컴퓨팅 서비스의 사용 자라는 이미지를 통해 사회적 이미지를 향상시킬 수 있다. 또한 자신에게 영향력을 미치는 사람들이 특정 ICT 자원 이용을 권장할 경우에는 더욱 그 가치를 인식하게 된다[11]. 다섯째, 개인의 혁신성 증대 및 혁신적인 조직 문화를 창출 할 수 있다. 혁신성은 새로운 ICT 서비스를 시도하고자 하 는 성향이다[12]. 혁신성이 강할수록 신규 ICT를 접해보고 자 하는 성향이 강하다 $[13,14]$.

클라우드 컴퓨팅 서비스 이용에 관해 제시된 장점들 중에 그린 ICT 실현을 위한 서비스 도입은 정부 주도 정책에 국 한되는 경향이 있어 본 연구에서는 제외하기로 한다. 또한 기존 연구들에서 비용 절감에 대한 장기적인 기대 효과를 다루고 있으나, 본 연구에서는 비용 측면을 클라우드 컴퓨 팅 서비스 단점에 중점을 두고 분석을 진행하고자 한다. 이 에 본 연구에서는 클라우드 컴퓨팅 서비스의 장점 중 유용 성과 사회적 영향/이미지, 그리고 혁신성과 클라우드 컴퓨팅 서비스의 단점 간에 상호작용을 분석하는 연구를 제시하고 자 한다.

\section{3 클라우드 컴퓨팅 서비스의 단점}

앞서 제시한 클라우드 컴퓨팅 서비스의 여러 장점들이 분 명 존재하지만 클라우드 컴퓨팅 서비스의 취약점들을 간과 할 수는 없으므로 이에 대한 분석이 필요하다. 기업이나 개 인이 클라우드 컴퓨팅 서비스를 도입하여 사용할 경우에 우 려되는 부분 중의 하나는 보안상의 위험이다. 클라우드 컴 퓨팅 서비스를 이용하는 단말기 별 보안상의 취약점을 가질 수 있고 공유된 데이터 자원의 손실 및 유출이 발생할 수 있다[15]. 또한 결함이 있는 서비스 제공자에게 종속되는 애 플리케이션의 위험, 관리자 및 관리 시스템의 취약점 등이 우려된다[15]. 클라우드 컴퓨팅 서비스의 보안에 관한 연구 들은 구체적이고 개별적으로 이루어지고 있으므로 본 연구 에서는 제외하기로 한다.

클라우드 컴퓨팅 서비스를 도입하고자 할 때 보안상 위험 외에 고려되는 점은 신규 서비스 도입에 따른 총체적인 비용 문제이다. 아무리 이상적인 기술이 등장하고 장기적으로 비 용 절감 효과가 예측되더라도, 예비 사용자들은 현실적인 비 용 분석을 필요로 한다. 비용은 크게 금전적 비용 (Monetary cost)과 비금전적 비용 (Non-monetary cost) 으로 구분된다 [16]. 금전적 비용은 클라우드 컴퓨팅 서비스를 이용하기 위 해 지불해야 하는 초기 서비스 도입 비용 및 유지관리 비용 이다[17]. 비금전적 비용은 적절한 서비스 제공업체를 검색하 는데 드는 비용과 신규 서비스에 직원들이 적응하는데 소요 되는 시간 비용, 노력 비용 등을 포함한다[16, 17, 18]. 
클라우드 컴퓨팅 서비스 이용에 드는 비용과 제공받게 될 서비스로 인한 혜택을 서로 고려하여 서비스 도입 여부를 결정지어야 할 것이다. 그러나 현재까지의 연구들은 클라우 드 컴퓨팅 서비스의 장점에 국한된 연구이거나 보안상 문제 를 짚어내는데 치중되어 있다. 따라서 본 연구에서는 클라 우드 컴퓨팅 서비스의 단점 중 비용 문제를 중심으로 혜택 과의 상호작용 효과에 관해 분석하고자 한다.

\section{4 인지된 가치 (Perceived value)에 관한 연구}

인지된 가치는 사용자가 제품의 전반적인 효용성을 평가 하는데 있어 지각하고 있는 가치를 의미한다[19]. 사용자가 어떠한 제품이나 서비스를 선택할 경우, 그에 대한 인지된 가치에 따라 무엇을 수용하고 무엇을 포기할지에 관한 결정 도 수반된다[19]. Lovelock은 그의 연구에서 인지된 가치는 서비스에 대한 혜택을 증대시키거나 서비스 구입 비용을 줄 여주는 역할을 한다고 언급하였다[20]. 기존 선행 연구들에 서 제품 및 서비스에 관한 인지된 가치는 고객 만족에 유의 미한 결과를 주는 연구들이 이루어졌다[17, 18, 21, 22]. 따라 서 본 연구에서는 클라우드 컴퓨팅 서비스의 도입 여부를 결정할 경우, 클라우드 컴퓨팅 서비스에 관한 혜택과 비용 이 인지된 가치에 영향을 주는지 살펴보고자 한다.

\section{3. 연구 가설 및 연구 모형}

\section{1 가설의 설정}

클라우드 컴퓨팅 서비스 이용을 통해 얻을 수 있는 혜택 과 서비스 이용에 소요되는 비용에 관한 상호작용 여부를 예측한다면 서비스 이용 여부를 결정지을 수 있다. 본 연구 에서는 클라우드 컴퓨팅 서비스의 혜택과 비용이 인지된 가 치에 미치는 영향에 대한 상호작용 효과를 실증적으로 분석 하기 위해 다음과 같이 연구 가설을 설정하였다.

1) 유용성에 관한 가설

유용성은 사용자가 새로운 기술을 도입함으로써 인지하게 되는 총 가치로 정의할 수 있다[23]. 윤승욱의 연구에서 모 바일 인터넷의 유용성과 사회적 영향이 각각 인지된 가치에 유의미한 영향을 주는 것으로 밝혀졌다[11]. 또한 TAM 모 델에서 인지된 유용성이 인지된 가치에 영향을 주는 것으로 제시되었다[8, 24].

클라우드 컴퓨팅 서비스를 이용함에 따라 사용자는 업무 성과 및 생산성 향상을 기대할 수 있는 반면 경제적, 시간 적 비용 등의 대가도 수반된다. 그러므로 본 연구에서는 클 라우드 컴퓨팅 서비스의 특성인 유용성 및 비용에 대한 가 설을 다음과 같이 제시하였다.

가설 1: 클라우드 컴퓨팅 서비스의 유용성은 인지된 가치에 정 $(+)$ 영향을 미칠 것이다.

가설 2: 클라우드 컴퓨팅 서비스의 유용성과 비용은 인지된 가치에 상호작용 효과를 미칠 것이다.
2) 사회적 영향/이미지에 관한 가설

현재 시장에서는 향후 클라우드 컴퓨팅과 관련된 매출이 증대될 것이라고 전망하고 있다[2]. 이러한 사회적 분위기는 기업이나 개인에게도 영향을 주어 클라우드 컴퓨팅 서비스 이용을 촉진하게 한다. 2003년에 제시된 UTAUT 모형에서 사회적 영향이 IT 기술의 이용에 영향을 주는 것이 확인되 었다. 유호선은 그의 연구에서 사회적 영향이 유비쿼터스 컴퓨팅 수용에 영향을 미치는 요인임을 밝혔다[10]. 또한 기 대하는 행위에 대한 보상을 해줄 수 있는 능력이나 처벌할 능력이 있는 사람들이 주변에 존재할 경우 개인들은 그들의 기대에 부응하고자 할 가능성이 있다[25, 26, 27]. 그러므로 본 연구에서는 클라우드 컴퓨팅 서비스의 특성인 사회적 영 향/이미지 및 비용에 대한 가설을 다음과 같이 제시하였다.

가설 3: 클라우드 컴퓨팅 서비스의 사회적 영향/이미지는 인 지된 가치에 정(+)영향을 미칠 것이다.

가설 4: 클라우드 컴퓨팅 서비스의 사회적 영향/이미지와 비 용은 인지된 가치에 상호작용 효과를 미칠 것이다.

3) 혁신성에 관한 가설

혁신성은 새로운 정보시스템을 시도하고 사용해보려는 성 향으로 설명된다[12]. 기존 선행연구에서 혁신성에 따라 혁 신적인 IT 자원의 채택 여부를 예측할 수 있는 것으로 나타 났다[28]. 그리고 이러한 혁신적 성향은 온라인 쇼핑몰의 구 매 결정에도 영향을 미친다[14]. 혁신성은 클라우드 컴퓨팅 서비스에 대한 가치를 인지하는데 있어 영향을 줄 것으로 보인다. 그러므로 본 연구에서는 클라우드 컴퓨팅 서비스의 특성인 혁신성에 대한 가설을 다음과 같이 제시하였다.

가설 5: 클라우드 컴퓨팅 서비스의 혁신성은 인지된 가치에 정 $(+)$ 영향을 미칠 것이다.

가설 6: 클라우드 컴퓨팅 서비스의 혁신성과 비용은 인지된 가치에 상호작용 효과를 미칠 것이다.

4) 비용 (Cost)에 관한 가설

클라우드 컴퓨팅 서비스를 이용하고자 할 경우에 초기 도 입 비용 및 유지관리 비용이 지불되어야 하며, 검색 비용 및 시간 비용이 소요된다 $[14,16]$. 기존 선행연구에서 인지된 비용이 인지된 가치에 유의미한 영향을 주는 것으로 밝혀졌 다[14]. 그러므로 본 연구에서는 클라우드 컴퓨팅 서비스의 특성인 비용에 대한 가설을 다음과 같이 제시하였다.

가설 7: 클라우드 컴퓨팅 서비스의 비용은 인지된 가치에 정 $(+)$ 영향을 미칠 것이다.

\section{2 연구 모형}

본 연구에서는 앞에서 설명한 클라우드 컴퓨팅의 특성 및 인지된 가치에 관한 연구들을 바탕으로 클라우드 컴퓨팅 서 비스의 혜택과 비용의 상호작용 관계를 나타내는 연구모형 을 다음과 같이 도출하였다. 


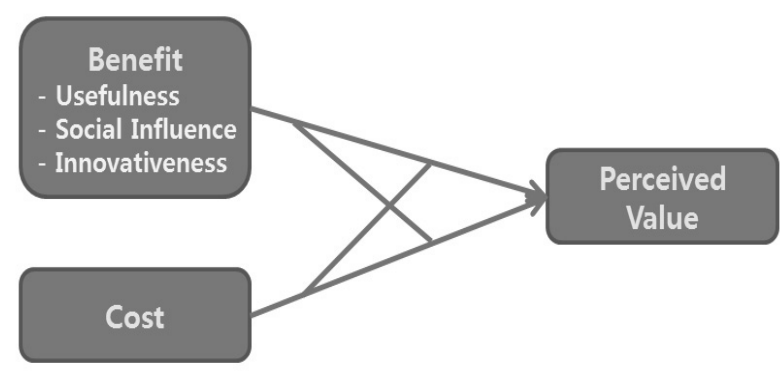

Fig. 1. Research Model

\section{4. 연구 방법}

\section{1 조사절차 및 자료수집}

본 연구는 클라우드 컴퓨팅 서비스가 사용자의 인지된 가 치에 미치는 영향에 관해 조사하는 것이다. 특히 선행연구 들이 주로 혜택과 비용에 대한 단순 회귀 분석을 실시한 것 에 비해, 본 연구에서는 혜택과 비용에 대한 상호작용 효과 를 동시에 고려함으로써 더욱 현실적인 모형을 수립하였다. 이에 따라 본 연구에서는 앞서 수립한 연구모형을 바탕으로 클라우드 컴퓨팅의 특성이 인지된 가치에 미치는 영향에 대 해 분석하고자 한다. 이를 위해 2012년 7월 1일부터 30일 동 안 클라우드 컴퓨팅 서비스에 대해 알고 있거나, 서비스를 이용한 경험이 있는 사용자를 대상으로 온라인 설문조사를 실시하였다. 본 연구에서는 인구통계학적 속성에 관련된 질 문을 제외한 모든 문항에 대하여 전혀 그렇지 않다(1)에서 매우 그렇다(5)까지의 5점 리커트 척도를 이용하였다. 또한 분석은 SPSS 18.0을 이용하여 기술통계분석, 신뢰성분석, 요인분석, 그리고 회귀분석을 실시하였다.

\section{2 변수의 조작적 정의}

본 연구에서는 선행연구를 바탕으로 클라우드 컴퓨팅 서 비스의 특성을 선별하였으며 독립변수로써 유용성, 사회적 영향/이미지, 혁신성, 비용을 설정하였다. 또한 종속변수는 인지된 가치로 설정하였다. 각 변수의 조작적 정의는 다음 의 표와 같다.

이상의 조작적 정의를 바탕으로 본 연구에서는 유용성을 '클라우드 컴퓨팅을 활용하면 나는 업무를 빠르게 처리할 수 있다', '클라우드 컴퓨팅을 활용하면 나는 업무를 효과적 으로 처리할 수 있다', '클라우드 컴퓨팅을 이용하면 업무를 수행하는데 있어서 시간과 노력을 절감시킬 수 있다', '클라 우드 컴퓨팅은 업무 처리에 유용하다'등으로 측정하였다 [23]. 사회적영향은 '나의 주변 사람들 중, 클라우드 컴퓨팅 을 이용하는 사람들이 그렇지 않은 사람들보다 권위가 있 다', '나의 주변 사람들은 클라우드 컴퓨팅을 사용해야 한다 고 여길 것이다', '나는 시대에 뒤떨어지지 않기 위해 클라 우드 컴퓨팅을 이용한다', '나는 클라우드 컴퓨팅에 대한 사 회적 평가가 좋아서 사용한다'등으로 측정하였다 $[8,10,11]$. 혁신성은 '나는 (IT 기기와 관련된) 신제품이 출시되면 주 변 사람들보다 먼저 사용해보는 경향이 있다', '나는 새로운
Table 1. Operational Definition of Variables

\begin{tabular}{c|l|c}
\hline Variables & \multicolumn{1}{|c|}{ Definition } & Reference \\
\hline \hline Usefulness & $\begin{array}{l}\text { Total usefulness to recognize that } \\
\text { they can get by using cloud } \\
\text { computing services }\end{array}$ & {$[8,23]$} \\
\hline $\begin{array}{c}\text { Social } \\
\text { Influence }\end{array}$ & $\begin{array}{l}\text { The degree of recognition to } \\
\text { believe that the important } \\
\text { acquaintances have to use cloud } \\
\text { computing services }\end{array}$ & {$[8,10,11]$} \\
\hline $\begin{array}{c}\text { Innovative } \\
\text { ness }\end{array}$ & $\begin{array}{l}\text { The degree that users are oriented } \\
\text { to innovation }\end{array}$ & {$[12,29]$} \\
\hline Cost & $\begin{array}{l}\text { The degree of economic and } \\
\text { temporal cost that are required } \\
\text { when cloud computing services is } \\
\text { introduced }\end{array}$ & {$[16-18]$} \\
\hline Perceived & $\begin{array}{l}\text { Overall perceived value about the } \\
\text { effectiveness of cloud computing }\end{array}$ & {$[19,20]$} \\
\hline Value
\end{tabular}

것에 대한 호기심을 가지고 있다', '나는 새로운 것을 경험 하고 시도해보는 것이 즐겁다'으로 측정하였다[29]. 한편, 비 용은 '클라우드 컴퓨팅을 이용하려면 비용을 지불해야 한 다', '클라우드 컴퓨팅을 이용하는데 드는 비용은 합리적이 다', '추후 클라우드 컴퓨팅 이용을 중지하려면 그에 대한 대가 비용을 지불해야 한다'으로 측정하였다[16-18]. 마지막 으로 인지적 가치는 '내가 지불한 비용에 비교할 때, 클라우 드 컴퓨팅을 사용하는 것은 가치가 있는 일이다', '내가 들 인 시간을 고려할 때, 클라우드 컴퓨팅 사용은 이득이다', '클라우드 컴퓨팅 이용은 나에게 긍정적인 가치를 부여한다' 로 측정하였다[19, 20].

\section{5. 분석결과}

본 연구는 선행연구의 한계를 극복하고 클라우드 컴퓨팅 서비스의 혜택과 비용의 상호작용 효과를 검정하기 위해 다 음과 같은 분석을 실시하였다.

\section{1 기술통계분석}

설문조사에 참가한 샘플의 인구통계학적 특성은 다음과 같다. 우선, 성별 분포는 남성이 전체 응답자의 약 $54.1 \%$ 로 106 명이 응답하였으며 여성이 약 $45.9 \%$ 였다. 연령은 30 대 응답자가 가장 많았으며, 20대 응답자와 40대 응답자가 고 르게 분포된 것으로 나타났다. 교육수준의 경우 전체의 $70.4 \%$ 가 석사학위 소지자로 나타난 것이 가장 큰 특징이다. 업종의 경우 금융업, 통신업 등 여러 업종을 대상으로 조사 를 실시하였다. 마지막으로 인구통계학적 특성 중 근무기간 의 경우 고르게 분포한 것을 알 수 있다.

\section{2 신뢰성 및 타당성 분석}

본 연구에서는 변수의 신뢰성과 타당성을 검정하기 위해 
Table 2. Regression Results of Benefit and Cost of Cloud Computing Service including Interaction Effect

$(\mathrm{n}=196)$

\begin{tabular}{|c|c|c|c|c|c|c|c|c|c|}
\hline & \multicolumn{2}{|c|}{$1^{\text {st }}$ Regression } & \multicolumn{2}{|c|}{$2^{\text {nd }}$ Regression } & \multicolumn{2}{|c|}{$3^{\text {rd }}$ Regression } & \multicolumn{3}{|c|}{$4^{\text {th }}$ Regression } \\
\hline & B & $\mathrm{SE}$ & B & $\mathrm{SE}$ & B & $\mathrm{SE}$ & B & $\mathrm{SE}$ & VIF \\
\hline Constants & $3.310 * * *$ & .293 & $.695^{+}$ & .380 & .250 & .386 & .457 & .388 & \\
\hline Gender & -.025 & .090 & .014 & .076 & .006 & .073 & -.009 & .072 & 1.254 \\
\hline Age & .074 & .051 & .027 & .043 & .033 & .042 & .022 & .041 & 1.637 \\
\hline Education & .093 & .064 & $.087+$ & .052 & $.087+$ & .051 & $.094^{+}$ & .049 & 1.070 \\
\hline Industry & -.031 & .023 & -.011 & .019 & -.001 & .019 & -.008 & .019 & 1.157 \\
\hline Tenure & -.011 & .037 & -.006 & .030 & -.014 & .029 & -.022 & .029 & 1.702 \\
\hline Usefulness (A) & & & $.380 * * *$ & .073 & $.371 * * *$ & .071 & $.309 * * *$ & .073 & 1.374 \\
\hline Social Influence (B) & & & $.228 * * *$ & .055 & $.159 * *$ & .056 & $.156 * *$ & .055 & 1.509 \\
\hline Innovativeness (C) & & & $.134 *$ & .058 & $.107+$ & .056 & $.143 *$ & .057 & 1.406 \\
\hline Cost $(\mathrm{M})$ & & & & & $.234 * * *$ & .062 & $.247 * * *$ & .065 & 1.441 \\
\hline $\mathrm{AX} \mathrm{M}$ & & & & & & & $-.221 *$ & .109 & 1.947 \\
\hline $\mathrm{B} X \mathrm{M}$ & & & & & & & -.138 & .089 & 2.059 \\
\hline $\mathrm{C} \mathrm{X} \mathrm{M}$ & & & & & & & $.172+$ & .089 & 1.816 \\
\hline Adjusted $\mathrm{R}^{2}$ & \multicolumn{2}{|c|}{ ".011 } & \multicolumn{2}{|c|}{ ".346 } & \multicolumn{2}{|c|}{2.388} & \multicolumn{3}{|c|}{.415} \\
\hline $\mathrm{F}$-value & \multicolumn{2}{|c|}{$1.426 * * *$} & \multicolumn{2}{|c|}{$13.878 * * *$} & \multicolumn{2}{|c|}{$14.758 * * *$} & \multicolumn{3}{|c|}{$12.551 * * *$} \\
\hline Change in adjusted $R^{2}$ & \multicolumn{2}{|c|}{.036} & \multicolumn{2}{|c|}{.336} & \multicolumn{2}{|c|}{.044} & \multicolumn{3}{|c|}{.035} \\
\hline Change in $\mathrm{F}$ & \multicolumn{2}{|c|}{$1.426 * * *$} & \multicolumn{2}{|c|}{$33.415 * * *$} & \multicolumn{2}{|c|}{$14.049 * * *$} & \multicolumn{3}{|c|}{$3.876 * *$} \\
\hline
\end{tabular}

Note) $+\mathrm{p}<.10, * \mathrm{p}<.05, * * \mathrm{p}<.01, * * * \mathrm{p}<.001$.

크롬바흐알파 (Cronbach's a) 계수를 통해 신뢰성을 측정하 였으며, 요인분석 (Exploratory factor analysis)을 통해 타당 성을 측정하였다. 특히 신뢰성은 변수들을 반복해서 측정했 을 경우 측정도구가 요인을 정확히 나타내는지를 알아보기 위한 것이다. 선행연구에서는 크롬바흐알파 계수가 탐색적 분야에서는 약 0.6 이상, 기초연구에서는 약 0.8 이상, 응용연구 에서는 약 0.9 이상이면 충분하다고 주장하였다[30]. 본 연구 에서는 탐색적으로 클라우드 컴퓨팅 서비스의 혜택과 비용에 대한 상호작용 효과를 검정하는 연구이기 때문에 0.6 이상의 신뢰성을 보일 경우 큰 문제가 없을 것으로 파악하고 있으 며, 모든 변수의 신뢰성에는 큰 문제가 없는 것으로 나타났 다. 반면에 본 연구에서는 타당성을 검정하기 위해 요인분석 을 실시하였다. 요인분석은 상관관계가 높은 변수를 끼리 묶 어 새로운 변수를 생성하여 그것을 통해 가설을 검정하는 것 을 의미한다. 본 연구에서 사용된 요인추출방식은 주성분분 석방법 (Principle component analysis)이며, 요인회전방식으 로 직각회전방법 (Varimax)을 사용하여 분석을 하였다.

\section{3 가설 검정 결과}

본 연구에서는 최근 폭발적인 관심을 가지고 있는 클라우 드 컴퓨팅 서비스에 대한 가설을 검정하기 위해 위계적 회귀 분석을 실시하였다. 통제변수로는 성별, 연령, 교육수준, 업종 그리고 근무기간을 포함시켰으며, 분석결과는 Table 2 와 같 다. 먼저 1 단계 회귀식은 통제변수만으로 구성하여 회귀분석 을 실시하였다. 분석 결과 특별히 유의한 변수는 나타나지 않았다. 2 단계 회귀식에서는 클라우드 컴퓨팅 서비스 선택의
중요 변수로 유용성, 사회적영향 그리고 혁신성을 선정하여 모델을 분석하였다. 분석 결과 유용성 $(\mathrm{B}=.380, \mathrm{t}=5.175$, $\mathrm{p}=.000)$, 사회적영향 $(\mathrm{B}=.228, \mathrm{t}=4.169, \mathrm{p}=.000)$, 혁신 성 $(\mathrm{B}=.134, \mathrm{t}=2.322, \mathrm{p}=.021)$ 로 모든 독립변수가 인지 된 가치에 유의미한 값을 갖고 있는 것으로 나타났다 $(\mathrm{F}=$ $12.551, \mathrm{p}=.000)$. 따라서 가설 1 , 가설 3 , 가설 5 는 모두 채 택되었다. 또, 비용측면을 포함한 3단계 회귀식에서 비용은 인지된 가치에 $\mathrm{B}$ 값이 .234 $(\mathrm{t}=3.748, \mathrm{p}=.000)$ 수준에서 유의미한 값을 갖는 것으로 나타났다.

4단계 회귀식에서는 클라우드 컴퓨팅 서비스의 혜택과 비 용의 상호작용 효과를 검정한 결과를 보여 주고 있다. 기존 연구에서는 주로 클라우드 컴퓨팅 서비스에 대한 혜택과 비 용을 따로 분석하였으나, 실제 우리가 클라우드 컴퓨팅 서 비스를 선택할 경우 대부분 장점과 단점을 동시에 고려하고 있다는 점에 착안하여 본 연구에서는 혜택과 비용에 대한 상호작용 효과를 탐색적으로 분석하였다. 분석 결과 클라우 드 컴퓨팅 서비스의 혜택인 유용성, 사회적영향, 혁신성과 비용의 상호작용 효과는 다음과 같다. 먼저 유용성과 비용 의 상호작용 효과의 경우 $\mathrm{B}$ 값이 - $.221(\mathrm{t}=-2.030, \mathrm{p}=$ .044)로 유의한 것으로 나타났다. 또, 혁신성과 비용의 상호 작용 효과의 경우 $\mathrm{B}$ 값이 $.172(\mathrm{t}=1.936, \mathrm{p}=.054)$ 수준에 서 유의한 것으로 나타났다. 하지만 사회적영향과 비용에 대한 상호작용 효과의 경우 $\mathrm{B}$ 값이 - $.138(\mathrm{t}=-1.549)$ 수준 이나 유의확률이 .123 임으로 통계적으로 유의한 상호작용 효과는 없는 것으로 나타났다. 따라서 본 연구의 가설 2 와 가설 6 은 채택되었으나, 가설 4 는 기각되었다. 
마지막으로 본 연구의 가설 7 을 검정하기 위해 분석한 결 과는 Table 3에 나타나 있다. 비용과 인지된 가치에 대한 회귀분석 결과 비용은 인지된 가치에 유의한 변수임이 밝혀 졌다 $(\mathrm{B}=.415, \mathrm{t}=6.395, \mathrm{p}=.000)$. 따라서 가설 7 은 채택 되었다.

Table 3. Regression Results of Cost of Cloud Computing Service on Perceived Value

$(n=196)$

\begin{tabular}{|c|c|c|c|c|c|}
\hline & \multicolumn{2}{|c|}{$1^{\text {st }}$ Regression } & \multicolumn{3}{|c|}{$2^{\text {nd }}$ Regression } \\
\hline & B & SE & B & SE & VIF \\
\hline Constants & 3.310 & .293 & 1.930 & .343 & \\
\hline Gender & -.025 & .090 & -.024 & .082 & 1.141 \\
\hline Age & .074 & .051 & .072 & .047 & 1.535 \\
\hline Education & .093 & .064 & .089 & .058 & 1.063 \\
\hline Industry & -.031 & .023 & -.011 & .021 & 1.102 \\
\hline Tenure & -.011 & .037 & -.025 & .034 & 1.683 \\
\hline Cost & & & .415 & .065 & 1.038 \\
\hline Adjusted $\mathrm{R}^{2}$ & \multicolumn{2}{|c|}{.011} & \multicolumn{3}{|c|}{.182} \\
\hline $\mathrm{F}$-value & \multicolumn{2}{|c|}{1.426} & \multicolumn{3}{|c|}{$8.254 * * *$} \\
\hline $\begin{array}{l}\text { Change in } \\
\text { adjusted } \mathrm{R}^{2}\end{array}$ & \multicolumn{2}{|c|}{.036} & \multicolumn{3}{|c|}{.171} \\
\hline Change in $\mathrm{F}$ & \multicolumn{2}{|c|}{1.426} & \multicolumn{3}{|c|}{$40.898 * * *$} \\
\hline
\end{tabular}

한편, 본 연구에서는 다중공선성 (Multicollineality)을 상 호작용 효과를 검정할 때, 평균중심화 (Mean-Centering)하 여 분석을 실시하였다. 다중공선성은 상호작용 항이 앞선 두 독립변수에 의해 주어지기 때문에 변수 간의 상관이 높 아질 경우 생기는 문제이다. 따라서 본 연구에서는 분산팽 창지수 (Variance Inflation Factor)를 통해 다중공선성을 분 석하였다. Table 2 의 분석 결과 본 연구에서 상호작용 항의 다중공선성은 큰 문제가 없는 것으로 나타났다.

\section{6. 결론 및 한계점}

본 연구에서는 실증 연구를 바탕으로 다음과 같이 결론 및 시사점과 한계점을 제시하고자 한다.

\section{1 결론 및 시사점}

본 연구는 최근 많은 관심을 가지고 있는 클라우드 컴퓨 팅 서비스에 대한 소비자 선택에 관해 연구를 진행하였다. 대부분 연구들은 클라우드 컴퓨팅 서비스에 대한 장점을 기 반으로 클라우드 컴퓨팅 서비스 선택에 영향을 주는 요인에 대해 연구하거나, 클라우드 컴퓨팅 서비스 선택 시 문제가 되는 요인에 대한 개별적인 연구를 진행하였다. 또, 이 두 변수들을 동시에 연구한 경우조차도 혜택과 비용에 대한 연 구를 독립적으로 수행하였다. 하지만 실제 클라우드 컴퓨팅
서비스를 선택하는 경우 대부분의 소비자는 혜택과 비용을 동시에 고려한다. 따라서 본 연구에서는 탐색적으로 실제 소비자 선택 시 두 요인을 동시에 고려하는 점에 착안하여 클라우드 컴퓨팅 서비스 선택 시 혜택과 비용에 대한 상호 작용 효과를 탐색적으로 분석하였다. 분석 결과는 다음과 같다.

첫째, 혜택 요인으로 본 연구에서 설정한 유용성, 사회적 영향 그리고 혁신성은 인지된 가치에 통계적으로 유의한 영 향을 미치는 것으로 드러났다. 따라서 가설 $1(\mathrm{~B}=.380, \mathrm{t}$ $=5.175, \mathrm{p}=.000)$, 가설 $3(\mathrm{~B}=.228, \mathrm{t}=4.169, \mathrm{p}=.000)$, 가설 $5(\mathrm{~B}=.134, \mathrm{t}=2.322, \mathrm{p}=.021)$ 는 채택되었다. 이러 한 결과는 실제 클라우드 컴퓨팅 서비스가 업무에 효과적일 경우 인지된 가치를 증가시켜 소비자 선택을 유도할 수 있 음을 보여준다고 할 수 있다.

둘째, 본 연구의 결과는 클라우드 컴퓨팅 서비스에 대한 인지된 가치는 비용이 높을수록 높아진다는 점을 밝혔다는 점이다. 따라서 가설 7 은 채택되었다 $(\mathrm{B}=.415, \mathrm{t}=6.395$, $\mathrm{p}=.000)$. 이것은 비용이 증가할수록 인지된 가치가 오히려 증가된다는 것을 의미한다. 즉, 소비자는 비용이 높은 서비 스일수록 가치를 더욱 기대한다는 것을 의미한다.

마지막으로 본 연구의 결과는 클라우드 컴퓨팅 서비스 선 택 시 혜택과 비용의 상호작용 효과를 탐색적으로 분석하였 다. 분석 결과 유용성과 혁신성에서 비용과의 상호작용 효 과가 나타났다. 하지만 두 변수의 의미는 매우 다른 흥미로 운 결과가 나타났다. 유용성의 경우 비용과의 상호작용 효 과는 음 $(-)$ 의 값이 나타났다 $(\mathrm{B}=-.221, \mathrm{t}=-2.030, \mathrm{p}=$ .044). 하지만, 혁신성의 경우 비용과의 인지된 가치에 대한 상호작용 효과가 정 $(+)$ 의 값이 나타났다 $(\mathrm{B}=.172, \mathrm{t}=$ $1.936, \mathrm{p}=.054)$. 즉, 우리의 결과는 클라우드 컴퓨팅 서비스 가 유용한 경우라고 하더라도 소비자들은 비용이 높은 경우 서비스를 가치 있게 생각하지 않는다는 것이나, 혁신성을 중요하게 생각하는 경우 비용의 높아도 가치 있게 생각한다 는 것을 뜻으로 매우 흥미로운 결과라고 할 수 있다. 따라 서 이와 같은 결과는 클라우드 컴퓨팅 서비스가 유용하더라 고 비용을 고려하려 소비자가 선택할 수 있음을 지적하고 있는 것이다. 하지만 혁신 그 자체에는 비용이 높아도 충분 히 가치 있다고 판단함으로써 혁신적인 서비스의 경우 충분 히 높은 비용을 지불할 의사가 있음으로 비용이 높더라도 소비자의 업무를 획기적으로 개선시켜 줄 경우 소비자는 이 러한 서비스를 선택할 수 있음을 의미한다고 할 수 있다. 실제로 매우 혁신적인 제품의 경우 소비자는 $\mathrm{AS}$ 의 불편함 이나 높은 가격에도 불구하고 더 가치 있는 제품이라고 생 각하여 구매하는 경우가 매우 높다고 할 수 있다.

\section{2 한계점}

하지만 본 연구에서는 다음과 같은 한계점도 존재한다. 먼저 동일방법편의 (Commom method bias) 문제를 극복하 지 못 하였다[31]. 동일방법편의란 서베이 방법론의 경우 주 관에 기초한 답을 하기 때문에 발생하는 분산의 왜곡으로 
발생하는 문제를 뜻한다. 따라서 종속변수를 2 차 자료 등으 로 수집하거나, 역선택 문항 등을 통해 이러한 문제를 해결 해야 할 것이다.

둘째, 본 연구에서는 클라우드 컴퓨팅 서비스에 대한 비 용측면 만을 고려하였지만, 실제 클라우드 컴퓨팅 서비스를 선택하려는 소비자에게 보안은 매우 큰 문제라고 할 수 있 다. 따라서 향후 상호작용 효과를 분석할 경우 보안 요인을 모형에 포함시켜 혜택 요인과의 효과를 분석한다면 통계적 인 의미와 함께 실제 소비자의 선택에 영향을 주는 매우 중 요한 요인에 대한 적합한 모형을 설계할 수 있을 것이다. 또한 클라우드 컴퓨팅 서비스 이용을 통한 금전적인 장점을 분석한 연구 모형도 고려해볼 수 있겠다.

셋째, 본 연구에서는 클라우드 컴퓨팅 서비스의 비용측면 에서 초기 서비스 도입에 소요되는 경제적/시간적 총 비용 을 중점적으로 분석하였으나, 서비스 도입 이후에 소요되는 비용에 관한 분석도 이루어진다면 의미있는 연구가 될 것이 다. 보안 위협에 따른 페널티 비용 등도 총 비용에 포함시 켜 연구를 진행한다면 클라우드 컴퓨팅 서비스의 유용성을 더욱 정확하게 확보할 수 있을 것이다.

클라우드 컴퓨팅 서비스는 향후 더욱 많은 관심을 받을 것이다. 기술적으로 충분한 구현이 가능하며, 클라우드 컴퓨 팅 서비스를 이용할 경우 많은 혜택이 소비자에게 돌아갈 수 있기 때문이다. 하지만 실제 소비자는 이러한 서비스를 선택할 경우 장점과 단점을 동시에 고려한다. 따라서 본 연 구에서처럼 혜택과 비용에 대한 상호작용 효과를 탐색적으 로 연구하는 것은 의미가 있다 하겠다. 현재 클라우드 컴퓨 팅 서비스 산업에 대한 기대치와 비교하여 추후 산업이 활 성화되거나 혹은 저조한 경우 실제 데이터를 바탕으로 새로 운 연구들을 진행하는 것도 의미가 있을 것이다. 또한 본 연구에서는 클라우드 컴퓨팅 서비스의 사회적 영향과 비용 의 상호작용 효과가 없는 것으로 나타났는데, 이에 대해 추 가적으로 면밀한 연구를 진행할 수 있겠다. 향후 클라우드 컴퓨팅 서비스에 대한 더욱 현실과 유사하고 세밀한 연구를 기대해 본다.

\section{참 고 문 헌}

[1] J. P. Lee and D. S. Choi, "New trends of the IT revolution, cloud computing has led to," LG Economic Research Institute, 2010.

[2] S. J, Park, M. Y. Yoon, Y. H. Lee, S. H. Jeong, and J. S. Hwang, "National dimension of ICT technology paradigm: Activation strategy of cloud computing," CIO Report, 2009.

[3] K Mobile Hyundai Research Institute, http://www.kmobile. co.kr/k_mnews/news/news_view.asp?tableid=IT\&idx=37753 7, 2012.

[4] J. H. Jeong, S. D. Kim, S, W. Kook, Y. K. Min, S. W. Son, S. J. Shin, H. D. Yang, and J. H. Lee, "Methods of improving the legal system to promote cloud computing," National IT Industry Promotion Agency, 2009.
[5] Gartner Group, "Assessing the security risks of cloud computing,” http://www.infoworld.com/article/08/07/02/gartner_ seven_cloudcomputing_security_risks_1.html, 2008.

[6] CPNI, "INFORMATION SECURITY BRIEFING 01/2010," htp://www.cpni.gov.uk/Docs/cloud-computing-briefing.pdf, 2010.

[7] NIST, http://www.csrc.nist.gov/groups/SNS/cloudcomputing /index.html

[8] V. Venkatesh and F. D. Davis, "A theoretical extension of the technology acceptance model: Four longitudinal field studies," Management Science, Vol.46, No.2, pp.186-204, 2000.

[9] H. S. Yoo, J. K. Kim, M. Y. Kim, O. B. Kwon, and H. K. Cho, "A study of factors influencing $u$-Market service acceptance for traditional market revitalization," Information Systems Review, Vol.10, No.2, pp.97-121, 2008.

[10] H. S. Yoo, M. Y. Kim, and O. B. Kwon, "A study of factors influencing ubiquitous computing service acceptance," Journal of Society for e-business Studies, Vol.13, No.2, pp.117-147, 2008.

[11] S. U. Yun, "The study on the acceptance decision factor of the mobile internet," Journal of Korean Society for Journalism \& Communication Studies, Vol.48, No.3, pp.274-476, 2004.

[12] M. Chang, W. Cheung, and V. Lai, "Literature derived reference models for the adoption of online shopping," Information \& Management, Vol.42, No.4, pp.543 - 559, 2005.

[13] B. F. Blake, K. A. Neuendorf, and C. M. Valdiserri, "Innovativeness and variety of internet shopping," Internet Research, Vol.13, No.3, pp.156-169, 2003.

[14] Ángel Herrero Crespo and Ignacio Rodríguez del Bosque, "The effect of innovativeness on the adoption of B2C E-commerce, A model based on the theory of planned behavior," Computers in Human Behavior, Vol.24, No.6, pp.2830-2847, 2008.

[15] E. Y. Jang, H. J. Kim, C. S. Park, and J. I. Lee, "The study on a threat countermeasure of mobile cloud services," Journal of Korea Institute of Information Security \& Cryptology, Vol.21, No.1, pp.177-186, 2011.

[16] W. Jen and K.. C. Hu, "Application of perceived value model to identify factors affecting passengers' repurchase intentions on city bus: A case of the Taipei metropolitan area," Transportation, Vol.30, No,3, pp.307-327, 2003.

[17] J. L. M. Tam, "Customer satisfaction, service quality and perceived value: An integrative model," Joumal of Marketing Management, Vol.20, pp.897-917, 2004.

[18] M. G. Gallarzaa and I. G. Saura, "Value dimensions, perceived value, satisfaction and loyalty: an investigation of university students' travel behavior," Tourism Management, Vol.27, No.3, pp.437-452, 2006

[19] V. A. Zeithaml, "Consumer perceptions of price, quality and value: a means ${ }^{-}$end model and synthesis of evidence," Journal of Marketing, Vol.52, No.3, pp.2-22, 1988. 
[20] C. Lovelock, "Services marketing," 4th ed., Prentice-Hall, 2001.

[21] J. L. M. Tam, "The moderating role of perceived risk in loyalty intentions: an investigation in a service context," Marketing Intelligence \& Planning, Vol.30, No.1, pp.33-52, 2012.

[22] C. F. Chen, "Investigating structural relationships between service quality, perceived value, satisfaction, and behavioral intentions for air passengers: Evidence from Taiwan," Transportation Research Part A, Vol.42, No.4, pp.709-717, 2008.

[23] E. M. Rogers, "Diffusion of innovations," 4th ed., New York: The Free Press, 1995.

[24] V. Venkatesh, and F. D. Davis, "A model of the antecedents of perceived ease of use: Development and test," Decision Sciences, Vol.27, No.3, pp.451-481, 1996.

[25] J. R. P. French and B. Raven, "The bases of social power," in The negotiation sourcebook, 2nd ed., HRD Press, pp.150-167, 2001.

[26] Triandis, H. C., "Interpersonal behavior," Brook/ColePub. Co., 1977.

[27] V. Venkatesh, M. G. Morris, G. B. Davis, and F. D. Davis, "User acceptance of information technology: Toward a unified view," MIS quarterly, Vol.27, No.3, pp.425-478, 2003.

[28] M. Y. Yi, K. D. Fiedler, and J. S. Park, "Understanding the role of individual innovativeness in the acceptance of IT-based innovations: Comparative analyses of models and measures," Decision Sciences, Vol.37, No.3, pp.393-426, 2006.
[29] C. Kim, M. Mirusmonov, and I. Lee, "An empirical examination of factors influencing the intention to use mobile payment," Computers in Human Behavior, Vol.26, No.3, pp.310-322, 2010.

[30] J. Nunnally, "Psychometric theory," 2nd ed., New York: McGraw-Hill, 1978.

[31] W. W. Park, M. S. Kim, S. M. Jeong, and K. M. Huh, "Causes and remedies of common method bias," Korean Journal of Management, Vol.15, No.1, pp.89-133, 2007.

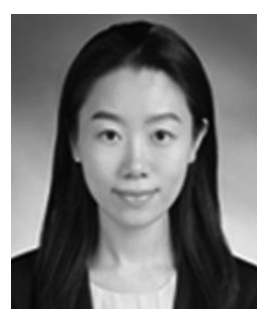

$$
\text { 박 소 연 }
$$

e-mail : soyeonpark@yonsei.ac.kr 2007년 성신여자대학교 정보공학, 국제통상(학사)

2010년 현 재 연세대학교 정보대학원 석사과정

관심분야: $\mathrm{e}-$ Business strategy, $\mathrm{BPR}$, 정보통신정책, 그린ICT

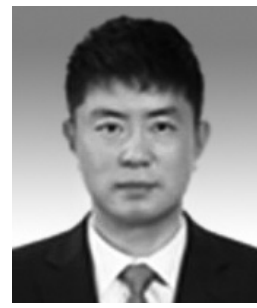

\section{김 용 원}

e-mail :kkjerry@yonsei.ac.kr 2012년 연세대학교 기술경영학(박사) 2012년 현 재 연세대학교 방송통신정책 연구소 선임연구원 관심분야: 기술경영, 기술혁신, $R \& D$ 매니지 먼트, 벤처창업 